\title{
ARTICLE
}

\section{Differences in Educational Expectations between Urban and Rural Junior High School Students: Individual, Family, and Social Structures}

\author{
Yuna Hou, Fuli Li \\ Southwest University, Chongqing 400715, China
}

\begin{abstract}
This paper studies the current differences in educational expectations between urban and rural students and explores the mechanism from the individual/family and school/society perspectives. The results show significant differences in expectations between rural and urban junior high school students for going on to higher education. In addition, urban students' educational expectations are higher than that of rural and migrant students. These differences are caused by the students' cognitive ability, family background, and school environment, among which the influence of family background is larger than that of cognitive ability, while the effect of the school's hukou structure is the most important influencing factor. The results suggest that building a desirable school education atmosphere, alleviating hukou segregation in schools, and strengthening the integration of widely diverse school populations are important approaches to promoting educational and social equity in China.
\end{abstract}

Best Evidence in Chinese Education 2022; 10(1):1315-1335.

Doi: 10.15354/bece.22.ar003.

How to Cite: Hou, Y., \& Li, F. (2022). Differences in educational expectations between urban and rural junior high school students: Individual, family, and social structures. Best Evidence in Chinese Education, 10(1):1315-1335.

Keywords: Educational Expectations, Rural-Urban Differences, Individual And Family Factors, Socio-structural Factors 
Hou \& Li. Educational Expectation between Urban and Rural Junior High School Students.

About Authors: Fuli Li, Faculty of Education, Southwest University, Chongqing 400715, China, E-mail: lifuli0630@163.com

Correspondence to: Yuna Hou, Research Institute for Education and Psychology of Southwestern Ethnic Groups \& Faculty of Education, Southwest University, Chongqing 400715, China. E-mail: nana860611@swu.edu.cn Conflict of Interests: None.

(C) 2022 Insights Publisher. All rights reserved.

cc) (i) (-) Creative Commons Non Commercial CC BY-NC: This article is distributed under the terms of the Creative Commons Attribution-NonCommercial 4.0 License

(http://www.creativecommons.org/licenses/by-nc/4.0/) which permits non-commercial use, reproduction and distribution of the work without further permission provided the original work is attributed by the Insights Publisher. 


\section{Introduction}

$\mathrm{E}$

DUCATION is the main channel for social mobility in modern society due to its important role in alleviating social stratification and promoting social fairness and justice. Following the promulgation of China's reform and opening-up policy, many advances have been made in the Chinese education system, and the overall education level in China has improved significantly. Simultaneously, the imbalance in education development has become increasingly prominent, including the gaps in educational attainment between urban and rural residents, which has attracted much scholarly attention. When measured by objective indicators, such as access to education and total schooling years, rural residents in China have always lagged behind urban residents in their educational achievements ( $\mathrm{Li}, 2014 \mathrm{a}$; Wu, 2011; Wu, 2013). Influenced by the increasingly popular ideological trend of "education is useless" in rural society, some rural young people subjectively deny the value of education. Their reluctance to pursue higher education may further widen the educational gap between urban and rural areas (Li \& $\mathrm{Wu}, 2015)$.

The low expectations for education of young people in rural China may have long-term consequences for their individual development. In recent years, the farreaching significance of educational expectations for social equity and justice in China has received little scholarly attention. Chinese society has always been more concerned about "who receives education," than about "who expects to receive education" and "how much education they expect" (Ding \& Wang, 2016). Chinese academia has long focused on indicators such as education acquisition and attainment, which measure equity in educational outcomes, but few studies have discussed the indicator of educational expectations, which measures equity in the educational process. Fewer studies have explored the differences in educational expectations between different household registration groups from a micro level. As an important indicator, educational expectations can effectively and stably predict educational and status attainment. If we can understand the generation of individuals' educational expectations, it will be easier for us to explain their educational attainment (Sewell \& Hauser, 1972). Therefore, exploring the differences in educational expectations between urban and rural residents provides an ideal breakthrough point to understand the current educational development gap between urban and rural areas, which has important practical significance for Chinese society.

The report of the 19th National Congress of the Communist Party of China underlined the importance of compulsory education in rural areas and proposed strategies to ensure that every child can equally enjoy high-quality education. Important modern social goals include supplying suitable education for all talented people, maximizing the development and use of social human capitals, supporting the welfare of the whole society, giving free rein to individual expertise, and satisfying individual pursuits. Individuals and their families must make wise educational choices to achieve these goals, but society must also provide sufficient educational opportunities to facilitate personal educational decisions. 
We used baseline data from the 2013-2014 China Education Panel Survey (CEPS) to discuss the current urban-rural differences in the educational expectations of junior high school students in China. This study explored the influence of students' personal cognitive ability, family background, and socio-structural factors (mainly school segregation caused by the household registration policy [hukou]) on the educational expectations of young people with household permanent residence in rural areas. In addition, we examined the role of these factors in narrowing the rural-urban gap in educational expectations. Hopefully, our findings will trigger an extensive discussion of the severe problem of low educational expectations among young rural residents in China and the potential consequences.

\section{Theoretical Framework and Literature Review}

Over the past 50 years, Western scholars have explored educational expectations from micro and macro perspectives. The micro perspective at the individual and family levels mainly originated from the Wisconsin model, while the Coleman report initiated a macro-level perspective of social structure.

\section{Personal and Family Factors Leading to Educational Expectations}

Since the 1950s, the body of research based on the Wisconsin school has accumulated several empirical studies modeling the formation and influencing factors of personal educational and occupational expectations. Early studies have mainly focused on the influence of individual and family factors on the formation of students' individual educational expectations. Gender, cognitive ability, and family socioeconomic status (SES) have been shown to be key factors affecting teenagers' educational expectations (Sewell, Haller, \& Straus, 1957). Later studies have tried to control for these three variables in the model when exploring individual educational expectations and status acquisition. In 1967, the Wisconsin school set up a linear regression model to study the influence of gender, cognitive ability, and family SES on individual educational expectations. The school then explored the influence of these four explanatory variables on individual educational attainment (Sewell \& Shah, 1967). As a mediating path, educational expectations have been shown to explain a large part of the impact of cognitive ability and family SES on individual educational attainment. Even after controlling for individual cognitive ability and family SES, educational expectations still have an independent and significant effect on educational attainment.

\section{Social Structures and Educational Expectations}

Early Wisconsin studies discussed the factors influencing educational expectations, focusing on the process of individual self-selection at the micro level with the assumption that individuals' educational achievements are determined by what they choose to do and how they do it. However, the reality is that individual educational choices are performed within a changing social structure; therefore, individuals' educational achievements are mainly influenced by what society allows them to do (Kerckhoff, 1976). The 
main criticism of the early Wisconsin body of research is that the models used are too sociopsychological and ignore the impact of macro-level socio-structural factors on individual educational expectations.

In 1959, Wilson launched a discussion of the influence of social class segregation on students' educational expectations. Wilson showed that even when personal and family backgrounds were controlled for, the social class composition within schools still had a significant impact on individual educational expectations. For example, students who attended schools with a majority of students from the dominant social class usually had higher educational expectations than students in schools with a majority of students from lower social classes (Wilson, 1959). In 1964, the Coleman report discussed ethnic segregation in American schools and found that social class segregation based on the ethnic composition of the school was the most important factor affecting students' academic development besides their family SES. The report found that American schools were ethnically segregated. For example, schools attended by White and ethnic minority groups (mainly Black students) had completely different ethnic composition ratios, and that minority students clustered in schools where students of the same ethnicity were concentrated. This kind of school segregation was detrimental to the academic achievements of minority students (Coleman, 1966).

Socio-structural factors affecting individual educational expectations include the students' living environment, school district and environment, and the institutions and policies in the labor market, which influence the distribution of different social groups in the social stratification system (Sewell, 1963). An important socio-structural factor leading to educational inequality is school segregation based on social groups' residence clusters. Students with different social characteristics gather in different school districts or schools, instead of being evenly distributed within the same school district or among schools. This informal school segregation (also known as school isolation) leads to significant differences in student composition between school districts/schools (Blau, 1977). On the one hand, this social structure will cause disparities in formal institutional arrangements, such as differences in community library facilities, teacher allocation, curricula, and school teaching arrangements. On the other hand, the social structure may also cause differences in informal social mechanisms, such as the local community's normative values, levels of aspiration, school value system, majority behavioral norms, and the school atmosphere created by peer groups. All of these differences affect individual educational expectations, especially for young people. These results are independent of individual abilities and family SES (Rogoff, 1953).

In the late 1960s, the Wisconsin body of research began to consider the impact of socio-structural factors, such as residence segregation, on educational expectations. The community, neighborhood, and school district environments (usually measured by urban-rural division, population size, and SES composition) where individuals live and studies have been found to have a significant effect on their educational and career expectations (Sewell, 1964; Sewell \& Armer, 1966). However, when factors such as students' gender, cognitive ability, and family SES are controlled for, the influence of these socio-structural variables decreases greatly, or even disappears. Based on this finding, Sewell, Hauser, Springer, and Hauser (2003) suggested that studies on educational expectations and attainment should focus on common process factors within school districts and schools, rather than background factors between school district and schools. 
School segregation is the result of residence division and the underlying phenomenon is the local competition of social groups for the resources and social status represented by schools (Fiel, 2015).

School segregation in the basic education system in China has become a common social phenomenon. The historic policy of "key schools" in China has led to quality differentiation in the public school system, while the "entering school nearby" policy has capitalized on the differentiated educational resources linked to house prices in the school district. Local residents select schools for their children by purchasing houses in high-quality school districts, which lead to the social segregation of school districts. As a result, the wealthy social class helps their children to enter high-quality schools by buying "school district housing," while children from the disadvantaged social class who cannot afford school district housing are forced to enter lower-quality schools. This leads to school segregation based on residence and school district (Feng \& Lu, 2010; Zheng \& Wang, 2014). This segregation based on household permanent residence (hukou) is one of the main forms of school segregation in China. On the one hand, the allocation of students with different hukou status is unbalanced among rural and urban regions. The distribution of students' hukou status among different regions largely decides the social class composition of these regions. The heterogeneity of social class composition in urban schools is higher than that in rural schools (Liang \& $\mathrm{Wu}, 2016$ ). On the other hand, with the large-scale migration of China's rural population to cities and the continuous adjustment of educational policies for the children of migrant workers, the government allows migrant students in compulsory education to study in places of residence other than their registered household permanent residence. However, China's current educational policy still sets a large threshold for admission and further education for non-local students because of limited urban educational resources. The children of rural migrant workers are often segregated from specific living areas, schools, and school districts because of the high cost of school selection in cities; therefore, they are often concentrated in private schools for migrant children with poor teaching facilities and low-quality teachers. At present, the social classes in China's rural and urban schools are highly segregated. As a result, rural or urban school students with disadvantaged family backgrounds tend to prematurely lose interest in education because of negative peer group influences caused by school segregation.

\section{Summary}

Rich empirical data have been accumulated in the mature Western research literature on students' educational expectations and their influencing factors. Personal characteristics, family backgrounds, and school structure have been found to be the main factors that jointly determine students' educational expectations and decisions. The educational stratification literature in China has mainly focused on result-directed indicators, such as educational attainment. The predictive role of educational expectations in educational attainment has not been explored, which ignores its importance as a breakthrough point for understanding the current differences in educational attainment among different groups in China. Most studies of educational expectations have not considered ruralurban differences, and those that have compared the educational expectations of social groups with different hukou status at the micro level are even rarer (Ding \& Wang, 
2016). In exploring the factors influencing educational expectations, such as the early Wisconsin body of research, most studies have focused on the process of individual self-selection and only examined the effects of individual and family backgrounds at the micro level (Liu, Zhang, \& Li, 2015; Wang \& Shi, 2014; Yang, Yao, \& Zhang, 2016). Few studies have explored the effects of macro-level social factors (Liang \& Wu, 2016; Wu, Hang \& Liu, 2017) and even fewer studies have measured macro and micro factors in addition to their interactions simultaneously (Huang, 2017). Some studies have tended to attribute the differences in educational expectations between urban and rural areas to the uneven distribution of educational resources influenced by educational policies and have not considered the effects of socio-structural factors (e.g., residence and school segregation), which are common concerns in Western studies of educational expectations.

This study used the Wisconsin educational attainment model based on the urban-rural education gap in China in an attempt to close the empirical research gap in Chinese educational expectations and explore the differences in educational expectations between rural and urban junior high school students from macro and micro perspectives.

\section{Research Design}

\section{Data}

This paper used baseline data from the 2013-2014 CEPS designed and implemented by the National Survey Research Center (NSRC) at Renmin University of China. The project took junior high school students in Grades 7 and 9 as the survey objects and applied a stratified multistage sampling design with probability proportional to size (PPS), in which four sampling units were selected in turn: i.e., county (school district); school; class; and students, parents, head teachers, main subject teachers, and school administrators. In total, 19,487 junior high school students in 438 classrooms from 112 schools in 28 counties (districts) in mainland China were selected in the baseline survey. This study used the data from student, parent, and school questionnaires, which were matched with student and school IDs.

\section{Research Questions and Hypotheses}

This study sought to answer the following questions: Are there any significant differences in educational expectations between rural and urban junior high school students? Can the students' personal characteristics, family environment, or socio-structural factors (such as school district/school segregation) explain these differences? Based on these research questions, this study proposed the following research hypotheses:

\section{Hypothesis 1: The educational expectations of rural hukou students are signifi- cantly lower than those of urban hukou students. \\ Hypothesis 2: Individual (such as gender and cognitive ability) and family fac- tors (such as SES) limit the educational expectations of rural hukou students.}


Hypothesis 3: Socio-structural factors (such as the school district's environment or school atmosphere) mean that the educational expectations of rural hukou students lag behind those of urban hukou students, even if the students' individual and family factors are controlled for in the model.

\section{Research Model and Variables}

We established the following linear regression model to answer these research questions and verify the research hypotheses:

$$
E D U \_E X P_{i j p}=\beta_{0}+\beta_{1} S T U_{-} T Y P E_{i}+\beta_{2} \beta_{i}+\beta_{3} S C H_{j}+\beta_{4} C T Y_{p}+\varepsilon_{i j p}
$$

\section{- Dependent Variable}

In this study, the dependent variable was the educational expectations of junior high school students $\left(E_{D U} E_{\text {EXP }}{ }_{\mathrm{ijp}}\right)^{\underline{I}}$. The CEPS student questionnaire asked junior high school students about their highest expected level of education using the question: "What is the highest degree of education you expect to receive?" Responses to this question had nine options: i.e., drop out, junior high school, technical/vocational senior high school, ordinary senior high school, college degree, Bachelor's degree, Master's degree, and doctoral degree. We recoded this categorical variable to form a dichotomous variable of "whether students expect a Bachelor's degree or higher," where yes = 1 and no $=0$.

\section{- Independent Variables}

\section{Student Type by Urban or Rural Hukou (STU_TYPE (S) $_{-}$}

The core explanatory variable of this study was the urban or rural category of students, which was used to examine the effect of registered household permanent residence (hukou) as a socio-structural factor. Due to the large population of migrant workers in China, the registered household permanent residence (Hukou $)^{\underline{2}}$ of some students differs from their current place of residence. Therefore, two dimensions could be observed among the students in this study: i.e., their household permanent residence (rural vs. urban hukou) and their place of residence during the survey. The latter dimension included information about individuals' rural-urban mobility. Based on our research needs, we recoded the original student category variable from the CEPS dataset to form a student category variable with three categories: (a) rural students, those with agricultural hukou (registered household permanent residence) from the local county (district); (b) migrant students, those with agricultural hukou from other counties (districts); and (c) urban students, those with nonagricultural hukou in local (district) or other counties (districts). We added dummy variables for the urban and rural student categories to the regression model and used urban students as the reference group to examine the differences in educational expectations between the two types of students.

\section{Personal and Family Background Factors $\left(\boldsymbol{\beta}_{\mathbf{i}}\right)$}

Based on the Wisconsin educational attainment model, we first examined the impact of students' personal and family factors on their educational expectations, including gender $($ male $=1$; female $=0$ ) and cognitive ability (the CEPS designed a set of cognitive 
ability test questions for junior high school students). The test questions did not involve specific memorization of knowledge related to school curricula, but focused on measuring the students' logical thinking and problem-solving abilities, including three language dimensions (graphics, calculation, and logic) with 11 constructs in total. The original cognitive ability test scores were transformed into standardized scores using item response theory with three parameters, leading to internationally comparable and nationally standardized results. Based on the high-to-low value ranking of this variable, we divided the students into three roughly equal groups to form a cognitive ability variable with three categories: low cognitive ability group $=1$; medium cognitive ability group $=2$; and high cognitive ability group $=3$. Finally, considering family SES, we used factor analysis to transform the variables of both parents' education and occupations, in addition to each family's economic conditions, into common factors to measure family SES. We divided the students into three roughly equal groups based on their high-to-low family SES scores to form a three-category variable to measure family SES: low-SES group $=1$; medium-SES group $=2$; and high-SES group $=3$.

\section{Socio-Structural Factors $\left(\mathrm{SCH}_{\mathbf{j}}\right)$}

To more deeply explore the sources of the differences in educational expectations between urban and rural junior high school students, we chose the following three sociostructural variables at the school district/school level: (a) school location: township and rural areas $=1$, marginal urban areas and urban-rural fringe $=2$; and cities/counties' central urban areas $=3$; (b) proportion of students in schools with agricultural hukou; and (c) proportion of students in schools with local county (district) hukou. There was a high degree of consistency between residence and school segregation; therefore, the school location variable could be used to examine the influence of the school district environment on students' educational expectations. The proportion of students in schools with agricultural hukou and the proportion of students in schools with local county (district) hukou measured the influence of peer groups on the students' educational expectations.

\section{- Control Variables}

To improve the quality of our model, we also controlled for other factors that may affect students' educational expectations at different levels: age, ethnicity $(1=$ ethnic minority, $0=$ Han nationality), number of siblings at the individual/family level; school properties $(1=$ public school, $2=$ private school $)$, school quality ranking $(1=$ poor to medium, 2 = upper middle, 3 = the best) at the school level, and district/county fixed effects $\left(\mathrm{CTY}_{\mathrm{p}}\right)$ at the district/county level.

The distribution of the main variables used in the study for the urban or rural student category variable is shown in Table 1.

The proportion of students with low cognitive ability or low family SES was much higher among rural and migrant student groups than among urban students. In contrast, students with high cognitive ability or high SES were clustered in the urban student group. Rural junior high school students were mostly clustered in rural schools, while urban junior high school students were mostly clustered in central city schools and migrant junior high school students were distributed among schools in both urban and rural areas. 


\begin{tabular}{|c|c|c|c|}
\hline Variable & $\begin{array}{l}\text { Rural } \\
\text { Students }\end{array}$ & $\begin{array}{l}\text { Migrant } \\
\text { Students }\end{array}$ & $\begin{array}{l}\text { Urban } \\
\text { Students }\end{array}$ \\
\hline Male & $51.57 \%$ & $53.57 \%$ & $50.98 \%$ \\
\hline Cognitive ability: Low & $39.68 \%$ & $35.29 \%$ & $26.73 \%$ \\
\hline Cognitive ability: Medium & $34.46 \%$ & $34.04 \%$ & $32.07 \%$ \\
\hline Cognitive ability: High & $25.86 \%$ & $30.67 \%$ & $41.20 \%$ \\
\hline SES: Low & $49.85 \%$ & $37.40 \%$ & $16.38 \%$ \\
\hline SES: Medium & $31.75 \%$ & $37.22 \%$ & $33.95 \%$ \\
\hline SES: High & $18.40 \%$ & $25.37 \%$ & $49.67 \%$ \\
\hline School location: Township/rural area & $56.57 \%$ & $28.33 \%$ & $19.07 \%$ \\
\hline School location: Urban-rural fringe & $25.06 \%$ & $35.88 \%$ & $22.64 \%$ \\
\hline School location: Central urban area & $18.37 \%$ & $35.79 \%$ & $58.30 \%$ \\
\hline Proportion of students in schools with agricultural hukou & $\begin{array}{l}0.729 \\
(0.173)\end{array}$ & $\begin{array}{l}0.538 \\
(0.237) \\
\end{array}$ & $\begin{array}{l}0.377 \\
(0.259)\end{array}$ \\
\hline $\begin{array}{l}\text { Proportion of students in schools with local county (district) } \\
\text { hukou }\end{array}$ & $\begin{array}{l}0.901 \\
(0.132) \\
\end{array}$ & $\begin{array}{l}0.605 \\
(0.243) \\
\end{array}$ & $\begin{array}{l}0.798 \\
(0.172) \\
\end{array}$ \\
\hline
\end{tabular}

Table 2. Descriptive Statistics for the Educational Expectations of Urban and Rural Junior High School Students.

\begin{tabular}{|c|c|c|c|c|c|c|c|c|c|}
\hline \multirow[b]{2}{*}{ Category } & \multicolumn{3}{|l|}{ Male } & \multicolumn{3}{|l|}{ Female } & \multicolumn{3}{|l|}{ Overall } \\
\hline & $\begin{array}{l}\text { Mean } \\
\text { (SD) }\end{array}$ & $\%$ & $\begin{array}{l}\text { Sample } \\
\text { Size }\end{array}$ & $\begin{array}{l}\text { Mean } \\
\text { (SD) } \\
\end{array}$ & $\%$ & $\begin{array}{l}\text { Sample } \\
\text { Size }\end{array}$ & $\begin{array}{l}\text { Mean } \\
\text { (SD) }\end{array}$ & $\%$ & $\begin{array}{l}\text { Sample } \\
\text { Size }\end{array}$ \\
\hline Rural & $\begin{array}{l}15.746 \\
(3.709)\end{array}$ & $53.62 \%$ & 4,129 & $\begin{array}{l}16.326 \\
(3.260)\end{array}$ & $64.93 \%$ & 3,972 & $\begin{array}{l}16.041 \\
(3.507)\end{array}$ & $59.17 \%$ & 8,101 \\
\hline Migrant & $\begin{array}{l}15.767 \\
(3.678)\end{array}$ & $55.14 \%$ & 1,119 & $\begin{array}{l}16.443 \\
(3.173)\end{array}$ & $68.45 \%$ & 1,008 & $\begin{array}{l}16.077 \\
(3.465)\end{array}$ & $61.45 \%$ & 2,127 \\
\hline Urban & $\begin{array}{l}16.725 \\
(3.523)\end{array}$ & $68.58 \%$ & 4,224 & $\begin{array}{l}17.179 \\
(3.067)\end{array}$ & $78.78 \%$ & 4,184 & $\begin{array}{l}16.951 \\
(3.311)\end{array}$ & $73.66 \%$ & 8,408 \\
\hline Overall & $\begin{array}{l}16.192 \\
(3.654)\end{array}$ & $60.47 \%$ & 9,742 & $\begin{array}{l}16.729 \\
(3.190)\end{array}$ & $71.64 \%$ & 9,164 & $\begin{array}{l}16.456 \\
(3.444)\end{array}$ & $65.96 \%$ & 18,636 \\
\hline
\end{tabular}

Note: The mean and standard deviation (SD) describe the average level and difference in educational expectations of junior high school students, respectively. The percentage describes junior high school students who expected to obtain a Bachelor's degree or higher.

In the schools attended by the rural student group in our study, more than $70 \%$ of the students came from rural areas and about $90 \%$ were registered in the local county. More than half of the students in the schools attended by the migrant student group in our study had rural household registration. About $60 \%$ of these students were registered in the local county/district, while in the schools attended by the urban student group in 
our study, only one third of the students were from rural areas and nearly $80 \%$ were registered in the local county/district.

\section{Results}

\section{Descriptive Statistical Analysis}

Without adding any control variables to our model, the proportion of junior high school students who expected to obtain a Bachelor's degree or higher showed a monotonically increasing trend among rural and urban students (Table 2). That is, rural junior high school students were less likely than migrant junior high school students to expect to obtain a bachelor's degree, while migrant junior high school students had lower expectations than urban junior high school students. Comparable results were obtained from the male and female samples, which is consistent with Hypothesis 1.

\section{Difference Test: Individual and Family Factors}

To verify the influence of individual and family factors on the differences in educational expectations between urban and rural junior high school students, we tested the significance of the differences in the mean values of their educational expectations. The results are reported by the students' cognitive ability and family SES.

\section{- Cognitive Ability}

Table 3 presents the pretest (difference-test) results, which took urban junior high school students as the reference group and reported the difference in the proportions of rural and migrant junior high school students and urban junior high school students expecting to obtain a bachelor's degree or higher. The z-test results showed the level of significance.

The results for the differences in educational expectations between urban and rural junior high school students without cognitive ability are shown in the bottom row of Table 3 for the full sample. The proportion of rural and migrant junior high school students who expected to obtain a bachelor's degree or higher were significantly lower than that of urban junior high school students. After grouping the students by cognitive ability, although the differences in educational expectations between urban and rural junior high school students were somewhat smaller, they did not disappear completely. There were still significant differences in educational expectations between urban and rural areas within each cognitive ability group. Specifically, for male students, the differences in educational expectations between urban and rural areas in the low cognitive ability group were reduced greatly, while obvious differences were observed in the educational expectations between urban and rural areas in the medium cognitive ability group. Interestingly, the differences in educational expectations between migrant and urban junior high school students in the high cognitive ability group were reduced significantly. These results showed that the experience of urban life and the school environment had a positive effect on the educational expectations of rural young people with high cognitive ability. The results for the female sample showed that the differences in educational expectations between urban and rural students in the medium and 
Table 3. Effects of Individual and Family Factors on the Educational Expectations of Obtaining a Bachelor's Degree or Higher among Urban and Rural Junior High School Students.

\begin{tabular}{|c|c|c|c|c|c|c|}
\hline \multirow{2}{*}{ Variab } & & & \multicolumn{2}{|l|}{ Male } & \multicolumn{2}{|l|}{ Female } \\
\hline & & & Rural & Migrant & Rural & Migrant \\
\hline \multirow[t]{12}{*}{$\begin{array}{l}\text { Cognitive } \\
\text { Ability }\end{array}$} & \multirow[t]{4}{*}{ Low } & Percentage & $0.407(0.012)$ & $0.394(0.024)$ & $0.524(0.013)$ & $0.543(0.028)$ \\
\hline & & \multirow{2}{*}{ Pretest } & diff. $=-0.084$ & diff. $=-0.098$ & diff. $=-0.092$ & diff. $=-0.073$ \\
\hline & & & $z=-4.436^{\star \star *}$ & $z=-3.455^{\star \star *}$ & $z=-4.597^{\star \star \star}$ & $z=-2.333^{* * *}$ \\
\hline & & Sample size & 1,591 & 419 & 1,572 & 328 \\
\hline & \multirow[t]{4}{*}{ Medium } & Percentage & $0.546(0.013)$ & $0.544(0.026)$ & $0.686(0.012)$ & $0.712(0.024)$ \\
\hline & & \multirow{2}{*}{ Pretest } & diff. $=-0.140$ & diff. $=-0.141$ & diff. $=-0.087$ & diff. $=-0.061$ \\
\hline & & & $z=-7.478^{\star \star \star}$ & $z=-5.015^{\star \star \star}$ & $z=-5.174^{\star \star \star}$ & $z=-2.396^{\star \star *}$ \\
\hline & & Sample size & 1,422 & 364 & 1,391 & 358 \\
\hline & \multirow[t]{4}{*}{ High } & Percentage & $0.708(0.014)$ & $0.756(0.023)$ & $0.795(0.013)$ & $0.798(0.022)$ \\
\hline & & \multirow{2}{*}{ Pretest } & diff. $=-0.114$ & diff. $=-0.065$ & diff. $=-0.104$ & diff. $=-0.101$ \\
\hline & & & $z=-7.091^{* \star *}$ & $z=-2.801^{* * *}$ & $z=-7.644^{\star \star \star}$ & $z=-5.197^{\star \star *}$ \\
\hline & & Sample size & 1,116 & 336 & 1,009 & 322 \\
\hline \multirow[t]{12}{*}{ SES } & \multirow[t]{4}{*}{ Low } & Percentage & $0.512(0.011)$ & $0.547(0.025)$ & $0.627(0.011)$ & $0.669(0.024)$ \\
\hline & & \multirow{2}{*}{ Pretest } & diff. $=0.006$ & diff. $=0.041$ & diff. $=-0.003$ & diff. $=0.039$ \\
\hline & & & $z=0.250$ & $z=1.299$ & $z=-0.122$ & $z=1.303$ \\
\hline & & Sample size & 1,944 & 411 & 2,104 & 393 \\
\hline & \multirow[t]{4}{*}{ Medium } & Percentage & $0.574(0.013)$ & $0.550(0.025)$ & $0.691(0.013)$ & $0.706(0.023)$ \\
\hline & & \multirow{2}{*}{ Pretest } & diff. $=-0.057$ & diff. $=-0.082$ & diff. $=-0.071$ & diff. $=-0.056$ \\
\hline & & & $z=-3.113^{\star * *}$ & $z=-3.000^{\star * *}$ & $z=-4.096^{\star \star *}$ & $z=-2.259^{* *}$ \\
\hline & & Sample size & 1,396 & 404 & 1,201 & 388 \\
\hline & \multirow[t]{4}{*}{ High } & Percentage & $0.527(0.018)$ & $0.559(0.028)$ & $0.643(0.019)$ & $0.674(0.031)$ \\
\hline & & \multirow{2}{*}{ Pretest } & diff. $=-0.251$ & diff. $=-0.219$ & diff. $=-0.218$ & diff. $=-0.187$ \\
\hline & & & $z=-13.266^{\star * *}$ & $z=-8.251^{* * *}$ & $z=-12.376^{\star * *}$ & $z=-7.334^{\star \star *}$ \\
\hline & & Sample size & 789 & 304 & 667 & 227 \\
\hline \multirow{4}{*}{\multicolumn{2}{|c|}{ Full sample }} & Percentage & $0.536(0.008)$ & $0.551(0.015)$ & $0.649(0.008)$ & $0.685(0.015)$ \\
\hline & & \multirow{2}{*}{ Pretest } & diff. $=-0.150$ & diff. $=-0.134$ & diff. $=-0.138$ & diff. $=-0.103$ \\
\hline & & & $z=-14.031^{* * *}$ & $z=-8.428^{* * *}$ & $z=-13.926^{\star * *}$ & $z=-6.968^{* * *}$ \\
\hline & & Sample size & 4,129 & 1,119 & 3,972 & 1,008 \\
\hline
\end{tabular}

Note: 1 . The reference group for the mean difference test in the table includes all urban students; $2 .{ }^{*} p<0.1,{ }^{* *}$ $p<0.05,{ }^{* * *} p<0.01$.

low cognitive ability groups were smaller, but the differences in educational expectations between urban and rural students in the high cognitive ability group showed little change compared with the full sample results.

The above results indicated that the observed differences in educational expectations between urban and rural junior high school students were not entirely due to 
their differing cognitive abilities. After controlling for cognitive ability, significant differences in educational expectations were still observed among rural and urban junior high school students with high cognitive ability. A possible reason for this finding is that some rural hukou students hope to live and work in rural areas in the future and the educational requirements for positions in the rural labor market are lower than those of the urban labor market, which may affect these students' judgment of the value and role of education. Therefore, we further tested the difference in educational expectations between rural junior high school students in the high cognitive ability group who want to stay in rural areas or small towns and those who want to stay in big cities or abroad to verify our findings. The results showed that the educational expectations of rural students who plan to live in big cities were significantly higher than those of their counterparts who plan to live in rural areas or small towns (diff. $=-0.209, \mathrm{z}=-9.394$ ), although both student groups were in the high cognitive ability group. Another possible reason is that even if they work in cities, most rural hukou residents can only enter the secondary labor market, in which education qualifications have a very limited effect on their social mobility opportunities. This may also affect rural students' judgment of the value and role of education, and subsequently their educational expectations ( $\mathrm{Li} \& \mathrm{Wu}$, 2015).

\section{- Family Background}

The bottom row of Table 3 for the full sample presents the results for the test of the differences in educational expectations between urban and rural junior high school students without grouping the students by family SES. The proportion of rural and migrant junior high school students who expected to obtain a bachelor's degree or higher were significantly lower than that of urban junior high school students. After grouping the students according to their family background, the differences in educational expectations between rural and migrant junior high school students and urban junior high school students with low SES were no longer significant regardless of gender. In other words, family SES explained the lower educational expectations of rural and migrant junior high school students from disadvantaged families. Although the differences in educational expectations between rural and migrant junior high school students and urban junior high school students with medium family SES were still significant, they were smaller than for the low SES group. Compared with the above results for cognitive ability, family background factors explained the differences in educational expectations between urban and rural junior high school students better than cognitive ability factors. However, it should be noted that the differences in educational expectations between rural and migrant junior high school students and urban junior high school students from advantaged family backgrounds increased compared with the results for the full sample. This result showed that the overall differences in educational expectations between urban and rural junior high school students were mainly reflected in the advantaged social class, reflecting the heterogeneity of the influence of family SES on the educational expectations of these students. That is, the positive influence of family background on urban students was greater than on rural and migrant students. A possible reason is that as the rural economy in China develops and parents of rural students increase their income and professional status gradually, they may still not know how to use their family capital to create a good educational atmosphere within the family. Such 
an atmosphere would help their children to form higher educational expectations compared with children of urban parents. Compared with rural families, Liu, Zhang, and Li (2015) found that urban parents' participation in their children's education is more helpful in increasing young people's educational expectations. To verify this result, we selected the "parental involvement" variable to measure the degree of activation of family capital and tested the difference in the degree of parental involvement between urban and rural junior high school students with advantaged family backgrounds. The results showed that the involvement of parents of rural junior high school students was significantly lower than that of parents of urban junior high school students (diff. $=-0.521, \mathrm{t}=$ -18.191 ), despite their similar family SES, while the differences in the degree of parental involvement between urban and rural students with poor family backgrounds were not significant.

\section{- Linear Regression Analysis: Socio-structural Factors}

The results of the previous difference test showed that students' personal and family factors, including gender, cognitive ability, and family SES, could explain only part of the differences in educational expectations between urban and rural junior high school students. Therefore, we established a linear regression model to further explore the influence of socio-structural factors, including the type of school district (urban vs. rural) and the household registration structure of school populations, on the level of and differences in educational expectations between urban and rural junior high school students.

Model 1 in Table 4 was a baseline model containing the control variables, which was used to test the differences in educational expectations between urban and rural junior high school students. The results showed that the proportion of rural and migrant junior high school students who expected to obtain a Bachelor's degree or higher was significantly lower than that of urban students. Specifically, rural and migrant junior high school students respectively had $4.6 \%$ and $5.3 \%$ lower educational expectations than did urban junior high school students. Models 2-5 controlled for the students' gender, gender and cognitive ability, gender and family background, and the three variables simultaneously, respectively. After controlling for individual and family factors, the difference in the proportion of students who expected to obtain a Bachelor's degree or higher between rural and migrant junior high students decreased, but did not disappear completely, which further verified the results of the previous difference test. In the next step, we explored the socio-structural factors that influence the difference in educational expectations between urban and rural junior high school students. Based on Model 5, Model 6 added the first socio-structural factor, that is, the urban/rural properties of the school districts. The proportion of junior high school students who expected to obtain a bachelor's degree or higher in the urban-rural fringe and the central urban areas was $5.4 \%$ and $6.8 \%$ higher than that in villages and towns, respectively. However, the addition of this variable to the model did not significantly change the significance of the differences in educational expectations between urban and rural junior high school students. This indicated that the school district environment had little influence on the differences in educational expectations between urban and rural junior high school students. This result is similar to early Wisconsin studies of the influence of residential segmentation on educational expectations. Based on Model 5, Model 7 added the se- 


\begin{tabular}{|c|c|c|c|c|c|c|c|c|}
\hline Explanatory Variable & Model 1 & Model 2 & Model 3 & Model 4 & Model 5 & Model 6 & Model 7 & Model 8 \\
\hline Rural Students & $\begin{array}{l}-0.046 \\
\star \star \star \\
(0.009) \\
\end{array}$ & $\begin{array}{l}-0.045 \\
\star \star \star \\
(0.009)\end{array}$ & $\begin{array}{l}-0.039 \\
\star * \star \\
(0.008)\end{array}$ & $\begin{array}{l}-0.034 \\
\star \star \star \\
(0.009)\end{array}$ & $\begin{array}{l}-0.029 \\
\star \star \star \\
(0.008)\end{array}$ & $\begin{array}{l}-0.022 \\
\star \star \star \\
(0.008)\end{array}$ & $\begin{array}{l}-0.008 \\
(0.009)\end{array}$ & $\begin{array}{l}-0.032 \\
\star \star \star \\
(0.008)\end{array}$ \\
\hline Migrant Students & $\begin{array}{l}-0.053 \\
\star \star \star \\
0.012) \\
\end{array}$ & $\begin{array}{l}-0.048 \\
* * \star \\
(0.012) \\
\end{array}$ & $\begin{array}{l}-0.039 \\
\star \star \star \\
(0.012) \\
\end{array}$ & $\begin{array}{l}-0.038 \\
\star \star \star \\
(0.012) \\
\end{array}$ & $\begin{array}{l}-0.030 \\
\star \star \\
(0.012) \\
\end{array}$ & $\begin{array}{l}-0.029 \\
* * \\
(0.012) \\
\end{array}$ & $\begin{array}{l}-0.017^{*} \\
(0.012)\end{array}$ & $\begin{array}{l}-0.019 \\
(0.012)\end{array}$ \\
\hline Male & & $\begin{array}{l}-0.112 \\
* * * \\
(0.007) \\
\end{array}$ & $\begin{array}{l}-0.110 \\
\star \star \star \\
(0.006) \\
\end{array}$ & $\begin{array}{l}-0.113 \\
\star \star \star \\
(0.007) \\
\end{array}$ & $\begin{array}{l}-0.111 \\
\star \star \star \\
(0.006) \\
\end{array}$ & $\begin{array}{l}-0.111 \\
\star \star \star \\
(0.006) \\
\end{array}$ & $\begin{array}{l}-0.111 \\
* * \star \\
(0.006) \\
\end{array}$ & $\begin{array}{l}-0.111 \\
\star \star \star \\
(0.006) \\
\end{array}$ \\
\hline Cognitive Ability: Medium & & & $\begin{array}{l}0.117 \\
* \star \star \\
(0.008) \\
\end{array}$ & & $\begin{array}{l}0.118 \\
\star \star \star \\
(0.008)\end{array}$ & $\begin{array}{l}0.115 \\
* \star * \\
(0.008)\end{array}$ & $\begin{array}{l}0.115 \\
\star \star \star \\
(0.008)\end{array}$ & $\begin{array}{l}0.117 \\
\star \star \star \\
(0.008)\end{array}$ \\
\hline Cognitive Ability: High & & & $\begin{array}{l}0.249 \\
* \star \star \\
(0.008) \\
\end{array}$ & & $\begin{array}{l}0.248 \\
\star \star \star \\
(0.008) \\
\end{array}$ & $\begin{array}{l}0.245 \\
\star \star \star \\
(0.008) \\
\end{array}$ & $\begin{array}{l}0.243 \\
\star \star \star \\
(0.008) \\
\end{array}$ & $\begin{array}{l}0.246 \\
* \star \star \\
(0.008) \\
\end{array}$ \\
\hline Ses: Medium & & & & $\begin{array}{l}0.022 \\
\star * \star \\
(0.009)\end{array}$ & $\begin{array}{l}0.017 \\
* * \\
(0.008)\end{array}$ & $\begin{array}{l}0.013 \\
(0.008)\end{array}$ & $\begin{array}{l}0.012 \\
(0.008)\end{array}$ & $\begin{array}{l}0.017 \\
\star * \\
(0.008)\end{array}$ \\
\hline Ses: High & & & & $\begin{array}{l}0.064 \\
\star \star \star \\
(0.009) \\
\end{array}$ & $\begin{array}{l}0.060 \\
\star \star \star \\
(0.009) \\
\end{array}$ & $\begin{array}{l}0.056 \\
* * * \\
(0.009) \\
\end{array}$ & $\begin{array}{l}0.052 \\
\star \star \star \\
(0.009) \\
\end{array}$ & $\begin{array}{l}0.059 \\
\star \star \star \\
(0.009) \\
\end{array}$ \\
\hline $\begin{array}{l}\text { School Location: } \\
\text { Urban-Rural Fringe }\end{array}$ & & & & & & $\begin{array}{l}0.054 \\
\star \star \star \\
(0.011) \\
\end{array}$ & & \\
\hline $\begin{array}{l}\text { School Location: } \\
\text { Central Urban Area }\end{array}$ & & & & & & $\begin{array}{l}0.068 \\
\star \star \star \\
(0.012) \\
\end{array}$ & & \\
\hline $\begin{array}{l}\text { Proportion of Students in } \\
\text { School with Agricultural } \\
\text { Hukou }\end{array}$ & & & & & & & $\begin{array}{l}-0.216 \\
\star \star \star \\
(0.025)\end{array}$ & \\
\hline $\begin{array}{l}\text { Proportion of Students in } \\
\text { Schools with Local County } \\
\text { (District) Hukou }\end{array}$ & & & & & & & & $\begin{array}{l}0.116 \\
* * * \\
(0.030) \\
\end{array}$ \\
\hline Control variables & Yes & Yes & Yes & Yes & Yes & Yes & Yes & Yes \\
\hline $\begin{array}{l}\text { District/County } \\
\text { Fixed Effects }\end{array}$ & Yes & Yes & Yes & Yes & Yes & Yes & Yes & Yes \\
\hline $\mathrm{R}^{2}$ & 0.064 & 0.076 & 0.111 & 0.078 & 0.113 & 0.115 & 0.117 & 0.114 \\
\hline Sample Size & 18,636 & 18,636 & 18,636 & 18,636 & 18,636 & 18,636 & 18,636 & 18,636 \\
\hline \multicolumn{9}{|c|}{$\begin{array}{l}\text { Note: } 1 . \text { Robust standard errors are presented in brackets; } 2 .{ }^{*} p<0.1,{ }^{* *} p<0.05,{ }^{* * *} p<0.01 ; 3 . \text { The refer- } \\
\text { ence group for the cognitive ability dummy variable is the low ability sample and the reference group for the } \\
\text { SES dummy variable is the low-SES sample. The reference group for the school location type dummy variable } \\
\text { is township and rural areas. }\end{array}$} \\
\hline
\end{tabular}

cond socio-structural factor used in this study, i.e., the proportion of students with agricultural household registration in schools. Compared with the urban/rural residence category variable, this school structural factor better explained the educational expectations of junior high school students. Specifically, for every 1\% increase in the proportion of students with agricultural household registration in schools, the proportion of junior high school students who expected to obtain a Bachelor's degree or higher decreased by $21.6 \%$. Moreover, the addition of this variable made the originally significant differences in educational expectations between rural and urban junior high school students completely disappear and greatly reduced the differences in educational expectations between migrant and urban junior high school students. After controlling for the 
students' individual and family factors, the proportion of peers with similar experiences of rural life within the schools attended by rural junior high school students largely explained the observed disadvantages in the educational expectations of rural junior high school students. If rural students with similar demographic characteristics and family background to urban students enter schools with a high proportion of urban students, their initial disadvantages in educational expectations will be reduced greatly. Based on Model 5, Model 8 added the third socio-structural factor of this study, i.e., the proportion of students in schools with residence registration in the local county/district. This variable had a strong and significant impact on the educational expectations of junior high school students. Specifically, for every $1 \%$ increase in the proportion of students in school with local registered household permanent residence, the proportion of students expecting to obtain a bachelor's degree or higher increased by $11.6 \%$. The addition of this school structural variable in the model eliminated the originally significant differences in educational expectations between migrant and urban junior high school students. After controlling for individual and family factors, the proportion of peers with similar experiences of rural-urban migration in the schools attended by migrant junior high school students largely explained the observed disadvantages in their educational expectations. If migrant students with similar demographic characteristics and family background to urban students enter schools with a high proportion of local students, their initial disadvantages in educational expectations will be greatly reduced.

\section{Discussion, Conclusion, and Policy Implications}

Based on baseline data from the 2013-2014 CEPS, this study explored the current differences in educational expectations between urban and rural high school students and their influencing factors in China. Micro-level individual/family factors and macrolevel socio-structural factors jointly determined the educational expectations of junior high school students and the different educational expectations between urban and rural areas.

First, the significant differences in educational expectations between rural and migrant junior high school students and their expectations for receiving higher education were significantly lower than those of urban junior high school students. Cognitive ability and family background only explained a small part of the differences in educational expectations between urban and rural junior high school students, with family background being more important than cognitive ability. The household registration structure (hukou composition) of the schools explained most of the differences in educational expectations between urban and rural junior high school students.

The government and all sectors of society should be concerned about the low educational expectations of young people in rural Chinese society identified in this study. First, with the rapid development of urbanization in China, young people will increasingly leave the countryside to find jobs in cities. When these young people compete with urban residents for work, their low educational expectations may hinder their career development. Opportunities for people with rural household registration status to become urban citizens are extremely limited. Indeed, this factor has been shown to have a significantly positive correlation with individuals' education level (Li, 2014b). Rural young people with low academic qualifications may become migrant workers in labor- 
intensive industries in the future, such as the manufacturing, construction, and service industries, where they have to take jobs with poor working conditions, low salaries, and low social status. Therefore, they may struggle to truly integrate into urban society (China Population and Family Planning Commission, 2010). In their future careers, most rural young people with low educational expectations will have to face this obstacle, which is difficult to overcome. Second, China is vigorously implementing a national rural revitalization strategy, in which economic developments and infrastructure construction in rural areas lead to increasingly higher requirements for experts in agricultural scientific knowledge and technology. However, the Chinese education system must be developed to cultivate the necessary expertise. Young people with hukou who do not go to work in cities but continue to live and work in rural areas may also be hindered in their rural career development because of their lower educational expectations.

Second, the results of this study showed that the difference in cognitive ability based on innate inheritance was not the main reason for the differences in educational expectations between urban and rural junior high school students in China. Conversely, a nurturing home environment (such as parental involvement) based on family SES (including parental education, occupation, and income) limited the expectations of rural students to receive higher education. Rural students' family background constraints made it difficult for them to make rational educational choices based on their own abilities. Today, science and technology are increasingly becoming decisive forces for socioeconomic development in global market competition. To maintain an advantage in global science and technology competition, China greatly needs well-educated experts in professional fields such as engineering, physics, and biology. However, if talented young people with high cognitive abilities from rural areas do not have correspondingly high educational expectations, it will be difficult for them to obtain the necessary education and training opportunities for desirable social occupations in the future. Thus, these young people will be unable to realize their full potential. This potential "talent loss" crisis will lead to wasted human resources in rural areas of China, which will affect the maximization of social welfare (Sewell, 1963).

Third, the environment of the school district where junior high school students live had little influence on their educational expectations. However, school segmentation based on registered household permanent residence, which is typically observed in the characteristics of peer groups within a school, had a major influence on the educational expectations of students with rural hukou. The total proportion of rural students with local registered household permanent residence greatly restricted their educational expectations, while the proportion of students with non-local registered household permanent residence in schools also greatly restricted migrant students' educational expectations. In China, segregation based on school institutions and policies is an intermediary mechanism in which macro-level socio-structural factors and micro-level family backgrounds work together on individuals' educational decision-making. Students with similar disadvantaged backgrounds tend to cluster in similarly poor schools or even within the same class, which leads to a corresponding segregation in the allocation of teachers, curricula, and teaching arrangements in schools. In addition, the school atmosphere created by most peer groups will differ. These differences may have an impact on the educational expectations of every young person in the school. It is difficult for Chinese schools to provide sufficient educational incentives for higher education to 
rural and migrant students because of school segregation caused by household registration institutions, which greatly inhibits their educational expectations.

The results of this study have the following implications for solving the problem of differences in educational expectations and attainment between Chinese urban and rural areas in the future. First, actively including educational guidance and career planning courses or programs in rural schools will effectively help to reduce the brain drain crisis in rural Chinese society. To bridge the gap in educational development between rural and urban areas, the Chinese government and policy makers must not only consider the problem of uneven distribution of educational resources (such as school facilities, materials, curricula, teachers, and management) but also pay attention to creating and improving the educational atmosphere of schools, so that schools can cultivate their students' educational expectations. Schools must provide rural students with information about educational opportunities and the value and future returns of higher education. Schools must also help their students obtain the required knowledge for their future career development, such as understanding the types of jobs they are suitable for and the educational qualification requirements for these jobs. This would prevent rural students from misjudging the value of education, leading them to think that "education is useless."

Any educational and vocational guidance also requires the participation of parents; therefore, rural parents should be helped to obtain more information and knowledge about educational and vocational opportunities to better help their children make rational educational decisions. Gradually alleviating and ending school segregation based on household registration will enhance the integration of widely diverse school populations, which will be an important channel for promoting educational and social equity in China. The government influences the educational decisions of individuals and their families through its educational policies. The finding of this study regarding the relationship between household registration segregation in junior high schools and the differences in educational expectations between urban and rural areas in China provides an empirical basis for the re-evaluation of current educational policies and their consequences. The composition and structure of the household registration system in urban schools are helpful to improve their students' educational expectations, while the household registration structure and composition of schools attended by rural students have a negative impact on their students' educational expectations (Kahlenberg, 2012). Therefore, it is important to promote the fairness of educational opportunities by reducing the degree of school segregation caused by the hukou household registration policy and increasing the diversity and heterogeneity of students' identities and backgrounds within schools to help vulnerable rural students obtain the same opportunities as urban students to enter urban schools with higher SES. In this respect, the reform of the existing household registration system in China must be deepened continually to weaken and gradually eliminate the restriction of household registration on the education of rural and migrant children. However, various forms of school quality differentiation must be eliminated to promote the balance of educational resources between regions, between urban and rural areas, and between schools. 
Notes:

1. The subscripts $i, j$, and $p$ in the model represent the individual/family, school, and district/county levels, respectively.

2. The CEPS dataset divided the student sample into eight types based on information about their household permanent residence (hukou type, rural vs. urban), the province where they live, and whether they live with their parents.

\section{References}

Blau, P.M. (1977). Inequality and Heterogeneity: A Primitive Theory of Social Structure. New York: Free Press. DOI: https://doi.org/10.1093/sf/58.2.677.

Coleman, J.S. (1966). Equality of educational opportunity. United States: US Department of Health, Education, and Welfare, Office of Education. DOI:

https://doi.org/10.3886/ICPSR06389.v3.

China Population and Family Planning Commission.(2010). Report on China's migrant population development. [Chinese]. Beijing: China Population Publishing House.

Ding, B.R., \& Wang, Y.J. (2016). Educational expectation differences in household registration-Based on a comparative study of four types of children. Education Science, 32(5):1-10. [Chinese].

Feng, H., \& Lu, M. (2010). Choosing a school by buying a home: Empirical evidence and policy implications of education's impact on housing prices. World Economy, 12:89-104. [Chinese].

http://www.cnki.com.cn/Article/CJFDTOTA L-SJJJ201012007.htm.

Fiel, J. (2015). Closing ranks: Closure, status competition, and school segregation. American Journal of Sociology, 121(1):126-170. DOI: https://doi.org/10.1086/682027.

Huang, C. (2017). The influences of family and school factors on urban-rural differences in educational aspirations. Sociological Review of China, 5(5):65-78. [Chinese].

Kahlenberg, R.D. (2012). The future of school integration: Socioeconomic diversity as an education reform strategy. New York: Cen- tury Foundation.

https://eric.ed.gov/?id=ED531911.

Kerckhoff, A.C. (1976). The status attainment process: Socialization or allocation? Social Forces, 55(2):368-381.DOI: https://doi.org/10.1093/sf/55.2.368

$\mathrm{Li}$, C.L. (2014a). The changing trend of educational inequality in China (1940-2010), Reexamining the urban-rural gap on educational opportunity. Sociologic Studies, 2014(2):65-89. [Chinese]. DOI: https://doi.org/10.19934/j.cnki.shxyj.2014.02 .004

Li, D. (2014b). Equal distribution of limited chances: A study of the citizenship shifts of Chinese peasants' children. Chinese Journal of Sociology, 34(4):91-118. [Chinese]. DOI: https://doi.org/10.15992/j.cnki.311123/c.2014.04.009

Li, T., \& Wu, Z.H. (2015). The new "theory of the uselessness of reading" in "rural China." Exploration and Free Views, 2015(5):11-12. [Chinese].

Liang, Y.C., \& Wu, X.Y. (2016). Education segregation and educational aspiration under China's Household registration system: A study based on CEPS 2014. Journal of Social Development, 2016(1):22-47, 242-243. [Chinese].

Liu, B.Z., Zhang, Y.Y., \& Li, J.X. (2015). Family SES and adolescent educational expectation: Mediating role of parental involvement. Peking University Education Review, 13(3):158-176, 192. [Chinese]. DOI: https://doi.org/10.19355/j.cnki.16719468.2015.03.011 
Hou \& Li. Educational Expectation between Urban and Rural Junior High School Students.

Rogoff, N. (1953). Social stratification in France and in the United States. American Journal of Sociology, 58(4):347-357. DOI: https://doi.org/10.1086/221171

Sewell, W.H. (1963). The educational and occupational perspectives of rural youth. Washington, DC: National Committee for Children and Youth, Department of Health, Education and Welfare.

https://eric.ed.gov/?id=ED019169.

Sewell, W.H. (1964). Community of residence and college plans. American Sociological Review, 29(1):24-38. DOI: https://doi.org/10.2307/2094638.

Sewell, W.H., \& Armer, J. M. (1966). Neighborhood context and college plans. American Sociological Review, 31(2):159-168. DOI: https://doi.org/10.2307/2090901.

Sewell, W.H., Haller, A.O., \& Straus, M.A. (1957). Social status and educational and occupational aspiration. American Sociological Review, 22(1):67-73. https://psycnet.apa.org/doi/10.2307/2088767

Sewell, W.H., \& Hauser, R.M. (1972). Causes and consequences of higher education: Models of the status attainment process. American Journal of Agricultural Economics, 54(5):851-861. DOI: https://doi.org/10.2307/1239228

Sewell, W.H., Hauser, R.M., Springer, K.W., \& Hauser, T.S. (2003). As we age: A review of the Wisconsin Longitudinal Study, 19572001. Research in Social Stratification and Mobility, 20:3-111. DOI: https://doi.org/10.1016/S02765624(03)20001-9

Sewell, W.H., \& Shah, V.P. (1967). Socioeconomic status, intelligence, and the attainment of higher education. Sociology of Education, 40(1):1-23. DOI:

https://doi.org/10.2307/2112184

Wang, F.Q., \& Shi, Y.W. (2014). Family background, educational expectation, and college degree attainment: An empirical study based on Shanghai survey. Chinese Journal of Sociology, 34(1):175-195. [Chinese]. DOI: 10.15992/j.cnki.31-1123/c.2014.01.011

Wilson, A.B. (1959). Residential segregation of social classes and aspirations of high school boys. American Sociological Review, 24(6):836-845. DOI: https://doi.org/10.2307/2088572

Wu, X.G. (2011). The household registration system and rural-urban educational inequality in contemporary China. Chinese Sociological Review, 44(2):31-51. DOI: https://doi.org/10.2753/CSA2162-05554 40202

Wu, Y.X. (2013). Educational opportunities for rural and urban residents in China, 19782008: Inequality and evolution. Social Sciences in China, 34(3):58-75. DOI: https://doi.org/10.1080/02529203.2013.8205 $\underline{55}$

Wu, Y.X., Huang, C., \& Liu, H. (2017). School socioeconomic segregation and educational expectations of students in China's junior high schools. Social Sciences in China, 38(3):112-126.

Yang, X.C., Yao, Y., \& Zhang, S. (2016). A study on the influence of family social status on adolescents' educational expectation: An empirical analysis based on CEPS 2014 survey data. China Youth Study, 13(3):67-73. [Chinese] DOI: https://doi.org/10.19633/j.cnki.11-2579/d. 2016.07.011

Zheng, L., \& Wang, S. (2014). School choice, capitalization of educational services, and residential segmentation: A reflection on the policy of neighborhood schooling. Education \& Economy, (6):25-32. [Chinese]. http://www.cnki.com.cn/Article/CJFDTOTA L-JYJI201406004.htm

The Chinese version of this article has been published in Global Education View, 2020, 49(3):90105. The English version has been authorized for being publication in BECE by the author(s) and the Chinese journal.

侯玉娜, 李馥丽. (2020). 城乡初中生教育期望的差异研究: 个人、家庭与社会结构的影响. 全 球教育展望, 49(3):90-105 
Hou \& Li. Educational Expectation between Urban and Rural Junior High School Students.

Received: 29 November 2021

Revised: 08 December 2021

Accepted: 06 January 2022 